\title{
Evaluation of the effect of Birth Preparation Program on birth satisfaction with „Salmon's Item List" scale
}

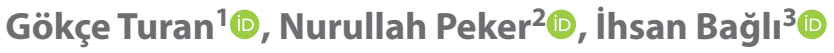 \\ ${ }^{1}$ Department of Obstetrics and Gynecology, Gazi University, School of Medicine, Ankara, Turkey \\ ${ }^{2}$ Department of Obstetrics and Gynecology, Dicle University, Faculty of Medicine, Diyarbakır, Turkey \\ ${ }^{3}$ Department of Obstetrics and Gynecology, Gazi Yaşargil Training and Research Hospital, Diyarbakır, Turkey
}

\begin{abstract}
Objectives: The aim of this study is to investigate the effects of a birth preparation program on birth satisfaction.

Material and methods: This cross-sectional study was conducted with patients who applied to our hospital between January 2018 and January 2019. A total of 164 pregnant women (Study Group) who applied for the birth preparation program and completed all training in our hospital and 152 pregnant women who did not apply for the birth preparation program and who did not know about such training (Control Group) were included in the study. Demographical data and obstetric parameters of the groups were recorded. All patients were evaluated with the Visual Analog Scale and Salmon's Item List scale 48 hours after the delivery. The scores of both groups were compared.

Results: There were no significant differences between the groups in terms of age, gravida, parity, gestational week of birth, the birth weight of infants, and $5^{\text {th }}$-minute APGAR scores. It was found that the Visual Analog Scale scores of the Control Group were significantly higher than in the Study Group. The Salmon's Item List scores of the Study Group were significantly higher than those of the patients in the Control Group $(<0.01)$.

Conclusions: The birth preparation program increases satisfaction during labor and decreases the traumas that may occur in the following births and increase comfort in the postpartum period. For this reason, such programs must be applied commonly to ensure that women can face both the birth and postpartum processes comfortably.
\end{abstract}

Key words: childbirth satisfaction; Salmon's Item List score; birth preparation; labor pain; antenatal education

Ginekologia Polska 2021; 92, 6: 417-422

\section{INTRODUCTION}

Birth preparation programs, which have been applied routinely since the beginning of the $20^{\text {th }}$ Century [1], are called under various names in several countries like birth preparation program, Expectant Parent Classes, Antenatal Parenthood Education, Antenatal Education, Childbirth Classes and Antenatal Classes. A significant percentage of pregnant women participate in birth preparation programs worldwide. The United States, the UK, Canada, Mexico, Brazil, Finland, Germany, Australia, Japan, Turkey, and China are among countries that actively implement these programs [2].

In most developed countries, birth preparation programs are planned to inform, train, support, and help parents to cope with the challenges that will appear in the maternity process and childbirth. Pregnancy and childbirth are among the most special and important experiences in women's lives. Regardless of the way a mother gives birth, it is important to support mothers to have a positive birth experience because it affects their self-esteem and mother-baby interaction. Satisfaction in the pregnancy process and labor action is the indicator of the quality of the medical institution and is also effective on women's health and the health of the newborn [3]. After a dissatisfied and traumatic birth, depression, post-traumatic stress disorder, less breastfeeding of the newborn, apathy to the newborn, and bad sex life can be observed [4].

Birth preparation programs have become an integral part of healthcare services, and constitute an important component of prenatal care. The contents of birth preparation programs vary among countries; however, the common target in all these programs is to prepare parents for childbirth and parenting [2].

Studies conducted on antenatal education are limited in number and have yielded conflicting results. Although

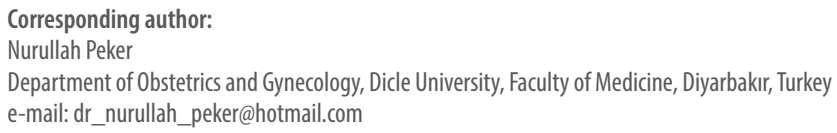


it was reported in previous studies that birth preparation program contributes to increasing women's satisfaction during labor, provides their active participation in this process, and also ensures that women face less psychological problems during the postpartum process [5-7], there are also other publications arguing that these training do not have any effects $[8,9]$.

Two wide-series literature reviews were published recently on measuring birth satisfaction. Various questionnaires used to assess birth satisfaction were compared in these two compilations, and it was reported that various questionnaires could be used for measuring birth satisfaction $[10,11]$. In this study, the "Salmon's Item List (SIL)" questionnaire was preferred to evaluate the satisfaction during childbirth. Because, as the questionnaire consists only of adjectives, it is also quite easy for postpartum women to answer. SIL was developed in 1992 [12] and was designed to measure women's feelings about birth and their birth experiences.

The purpose of the present study was to investigate the effect of the Birth Preparation Programs on birth satisfaction

\section{MATERIAL AND METHODS}

This cross-sectional study was conducted with patients who applied to the second clinic of Kırıkhan State Hospital, Hatay, Turkey between January 2018 and January 2019. The study was approved by the ethics committee (Ethics Committee Decision No: 2019/15). Informed consent was given by all participants before their enrolment into our study. A total of 164 pregnant women (Study Group), who applied for birth preparation programs, which was actively run in our hospital, who completed all relevant training in our hospital, and who gave birth in our hospital; and 152 pregnant women, who did not apply for birth preparation programs previously, who did not know about such training and who gave birth in our hospital (Control Group), were included in the study. Those who delivered their babies with cesarean section upon the request of the mother, those who gave birth before the 34th week of pregnancy, who had chromosomal and structural malformations in the fetus, those who gave intrauterine stillbirth, those with postpartum bleeding and severe preeclampsia, and those with additional diseases due to pregnancy were excluded from the study. Also, pregnant women who did not want to participate in the study or who did not complete our birth preparation program were not included in the Study Group. The gestational weeks of all included patients were calculated according to the last menstrual dates. In pregnant women who did not know their last menstrual dates, the gestational week was calculated by using the fetal crown-rump length measurement in the first trimester. The patients in both groups gave birth in the same maternity rooms and under the same conditions. Episiotomy was performed routinely for all nulliparous patients. No episiotomy was performed for multiparous patients. No patients received analgesics before birth.

The age, gravida, parity, birth shape, birth weight of the baby, $5^{\text {th }}$-minute APGAR scores, birth weeks, education and income status, and professions of all patients were recorded; and both groups were compared with each other. All patients were evaluated 48 hours after birth for estimating how much pain they suffered and for evaluating their pain severity with the Visual Analog Scale. The patients in both groups were also evaluated in terms of birth satisfaction by applying the SIL scale face-to-face 48 hours after the delivery. The Visual Analog Scale (VAS) values and SIL scores of both groups were also compared.

\section{Birth preparation program}

Our hospital has a birth preparation program class that was approved by the Ministry of Health of the Republic of Turkey in November 2018. Pregnant women between 16-20 weeks are informed about the program, and those who wish to participate in it are enrolled. All pregnant women, who have their first pregnancy, multiparous and have given normal birth previously, or who have the previous form of delivery as cesarean section, can participate in this program. Each participant is subjected to a three-hour training session once a month for four months. These sessions are provided to a group of up to 10 women. There is a projection system in the training room, and pregnant women are informed with a presentation about the pregnancy process, birth, and postpartum period. Besides, there are also whiteboards, educational models, Pilates balls, and yoga mats in the training room. A psychologist, a physiotherapist, a dietitian, an obstetrician, a child development specialist, and two midwives participate in the program. The main themes in each session are summarized in Table 1 . A certificate is given to the participants who complete all sessions at the end of the program. The program is free. There is no obligation to participate and participation is voluntary.

\section{Salmon's Item List (SIL)}

In this study, the form of SIL that was translated from the English version was used [12]. The themes measured in the scale are the feelings of women regarding their labor and delivery experiences. There are 20 items that comprise contrasting adjective pairs (i.e. fulfilled-not fulfilled, easy-not easy, etc.). The SIL scale is shown in Table 2. Each item was rated between 1 and 7 points according to the satisfaction status; $2^{\text {nd }}, 3^{\text {rd }}, 4^{\text {th }}, 5^{\text {th }}, 7^{\text {th }}, 8^{\text {th }}, 9^{\text {th }}, 10^{\text {th }}, 12^{\text {th }}$, $13^{\text {th }}, 14^{\text {th }}, 17^{\text {th }}, 18^{\text {th }}$, and $20^{\text {th }}$. The points given to the questions were subtracted from 8 points (in this way, the lowest point was 1, the highest was 7 points), and all points were averaged. This average value was then multiplied by 20 , 
Table 1. Headings of the courses in Birth Preparation Programs

Structure of female and male reproductive organs, and the formation of pregnancy

Session 1 Maternal changes during pregnancy and recommendations

Intrauterine fetal development and growth

Labor preparation plan

Stages of labor

Drug-free methods used in coping with labor pains

Caesarian birth

After $20^{\text {th }}$ gestational week (3-Session Training)

Session 2 - Breathing exercises during pregnancy (Practice)

- Massage techniques (Practice)

- Exercise during pregnancy (Practice)

- Birth yoga (Practice)

- How to bathe the infant?

- Clothing the infant

- Massage to the infant

- Delivery room and maternity ward trip

Postpartum period

Session 3

Nutrition in the postpartum period

Breast milk and breastfeeding

Care of the newborn

and 20 was subtracted from the resulting value. As a result, the calculated values ranged from the lowest 0 points to the highest 120 points. Although SIL was actively used in many countries, the German Salmon's Item List (SIL-Ger) version was published in 2001 by Stadlmayr et al., and the (SIL-Ger) computational system was used in this study [13]. SIL-Ger scores $\geq 70$ suggested satisfactory experience; however, $<70$ scores were considered to be an unsatisfactory experience $[13,14]$.

\section{Visual Analog Score (VAS)}

The meaning of the numbers ranging from 0 to 10 on a $10-\mathrm{cm}$ line was explained to the patients. No pain at all was scored with 0 , the most severe pain felt in life was scored with 10 points, and moderate pain was scored with five points. The patients were asked to mark their pain on this $10-\mathrm{cm}$ line according to these explanations.

\section{Statistical analysis}

The Statistical Package for Social Sciences 20.0 (SPSS Inc.; Chicago, IL, USA) was used for statistical analyses. The distribution of the data was evaluated with the Kolmogorov-Smirnov test. Descriptive statistical methods (mean, standard deviation) were used in the evaluation of normally distributed data, and the independent t-test was used to compare paired groups. If the distribution of variables was not normal, the Mann-Whitney U-test was used. The results were evaluated at a $p<0.05$ significance level.

\begin{tabular}{|c|c|c|}
\hline \multirow{2}{*}{$\begin{array}{l}\text { Items } \\
1\end{array}$} & \multicolumn{2}{|c|}{ Original English version } \\
\hline & Disappointed & Not disappointed \\
\hline 2 & Fulfilled & Not fulfilled \\
\hline 3 & Enthusiastic & Not enthusiastic \\
\hline 4 & Satisfied & Not satisfied \\
\hline 5 & Delighted & Not delighted \\
\hline 6 & Depressed & Not depressed \\
\hline 7 & Happy & Not happy \\
\hline 8 & Excited & Not excited \\
\hline 9 & Good experience & Bad experience \\
\hline 10 & Coped well & Did not cope well \\
\hline 11 & Cheated & Not cheated \\
\hline 12 & In control & Not under control \\
\hline 13 & Enjoyable & Not enjoyable \\
\hline 14 & Relaxed & Not relaxed \\
\hline 15 & Anxious & Not anxious \\
\hline 16 & Painful & Not painful \\
\hline 17 & Easy & Not easy \\
\hline 18 & Time going fast & Time going slowly \\
\hline 19 & Exhausted & Not exhausted \\
\hline 20 & Confident & Not confident \\
\hline
\end{tabular}

\section{RESULTS}

A total of 990 pregnant women applied to the birth preparation program of our hospital between January 2018 and January 2019; and 180 of these pregnant women completed all three sessions, received the participation certificate, and gave birth in our hospital. Since 12 of the 180 pregnant women gave birth before 34 weeks, two had fetal abnormalities, one had an intrauterine stillbirth, and one had postpartum atony, 16 pregnant women were excluded from the study, and a total of 164 pregnant women were included in the Study Group. The Control Group included 152 pregnant women who gave birth in our hospital between the same dates and did not apply for any birth preparation program during pregnancy, which means that 316 patients were included in the study in total. The demographic data of both groups are listed in Table 3.

The mean age of the Study Group was $26.3 \pm 0.9$ and that of the Control Group was $25.4 \pm 1$.2. No significant differences were detected between the groups. There were no significant differences between the groups in terms of gravida, parity, gestational weeks of birth, birth weight of the infant, and $5^{\text {th }}$-minute APGAR scores. In both groups, pregnant women who had never received education at schools were at the largest number (the study group 19.5\%, and Control Group 23\%). Most of the groups had housewives (the Study Group 48.1\%, and Control Group 48\%). 


\begin{tabular}{|c|c|c|c|}
\hline & $\begin{array}{l}\text { Study Group } \\
\text { (n: 164) }\end{array}$ & $\begin{array}{l}\text { Control Group } \\
\text { (n: 152) }\end{array}$ & $\mathbf{P}$ \\
\hline Age $($ mean $\pm S D)$ & $26.3 \pm 0.9$ & $25.4 \pm 1.2$ & 0.53 \\
\hline Gravida & $1.8 \pm 1.1$ & $1.9 \pm 0.9$ & 0.42 \\
\hline Parity (mean $\pm S D$ ) & $1.4 \pm 0.2$ & $1.3 \pm 0.5$ & 0.33 \\
\hline $\begin{array}{l}\text { Gestational age at delivery } \\
\text { (week } \pm \text { SD) }\end{array}$ & $38.2 \pm 0.6$ & $38.6 \pm 0.5$ & 0.25 \\
\hline \multicolumn{4}{|l|}{ Delivery method (n, \%) } \\
\hline - Cesarean section (n) & $16(9.7)$ & $14(9.2)$ & 0.62 \\
\hline - Vaginal birth (n) & $148(90.2)$ & $138(90.7)$ & 0.53 \\
\hline Birth weight $(\mathrm{g} \pm \mathrm{SD}$ ) & $3375 \pm 230$ & $3220 \pm 150$ & 0.48 \\
\hline $\begin{array}{l}5^{\text {th }} \text {-minute APGAR score } \\
(\text { mean } \pm S D)\end{array}$ & $9.0 \pm 0.5$ & $9.2 \pm 0.5$ & 0.52 \\
\hline \multicolumn{4}{|l|}{ Education (n, \%) } \\
\hline - None & $32(19.5)$ & $35(23)$ & \multirow{6}{*}{$\mathrm{N} / \mathrm{A}$} \\
\hline - Primary & $19(11.5)$ & $12(7.8)$ & \\
\hline - Secondary & $40(24.3)$ & $34(22.3)$ & \\
\hline - High & $38(23.1)$ & $41(26.9)$ & \\
\hline - University & $32(19.5)$ & 29 (19) & \\
\hline - Master's degree & $3(1.8)$ & $1(0.6)$ & \\
\hline \multicolumn{4}{|l|}{ Profession (n, \%) } \\
\hline - Housewife & $79(48.1)$ & $73(48)$ & \multirow{5}{*}{ N/A } \\
\hline - Unemployed & $12(7.3)$ & $15(28.8)$ & \\
\hline - Part-time employee & $29(17.6)$ & $22(14.4)$ & \\
\hline - Full-time employee & $24(14.6)$ & $25(16.4)$ & \\
\hline - Other & $20(12.1)$ & 17 (11.1) & \\
\hline \multicolumn{4}{|l|}{ Income $(n, \%)$} \\
\hline - Subsistence wage & $48(29.2)$ & $52(34.2)$ & \multirow{3}{*}{$\mathrm{N} / \mathrm{A}$} \\
\hline - Middle & $75(45.7)$ & $72(47.3)$ & \\
\hline - High & $41(25)$ & $28(18.4)$ & \\
\hline
\end{tabular}

SD — standard deviation; N/A — not applicable

The VAS and SIL scores of the groups are listed in Table 4. TheVAS scores of the pregnant women in the Control Group were found to be significantly higher than those in the Study Group $(9.1 \pm 0.5,7.0 \pm 0.6$, respectively; $p<0.01)$. Also, the SIL scores of the Study Group were significantly higher than the patients in the Control Group ( $p<0.01$ ). A total of $90.8 \%$ of the patients who participated in the Study Group had SIL scores above 70 , and only $27.6 \%$ of the Control Group had SIL scores above 70. The demographic data of the pregnant women who had SIL scores more than 70 and those under 70 are listed in Table 5 . In this respect, there were no differences between the groups in terms of age, gravida, parity, week of delivery, birth weight of the infant. However, the $5^{\text {th }}$-minute APGAR scores of the pregnant women with SIL scores above 70 were significantly higher than those with lower than $70(p<0.001)$. Also, the number of pregnant
Table 4. Comparison of Visual Analog Scale and Salmon's Item List scores of the groups

\begin{tabular}{|l|l|l|l|}
\hline & $\begin{array}{l}\text { Study Group } \\
\text { (n: 164) }\end{array}$ & $\begin{array}{l}\text { Control Group } \\
\text { (n: 152) }\end{array}$ & P \\
\hline VAS score (mean \pm SD) & $7.0 \pm 0.6$ & $9.1 \pm 0.5$ & $<0.01$ \\
\hline SIL-Ger score (mean \pm SD) & $108.5 \pm 4.2$ & $79 \pm 3.5$ & $<0.01$ \\
\hline SIL-Ger score $\geq 70(n, \%)$ & $149(90.8 \%)$ & $42(27.6 \%)$ & $<0.01$ \\
\hline
\end{tabular}

VAS — Visual Analog Scale; SIL — Salmon's Item List

Table 5. Comparison of those with Salmon's Item List score $\geq 70$ and $<70$

\begin{tabular}{|c|c|c|c|}
\hline & $\begin{array}{l}\text { SIL-Ger score } \\
\geq 70 \text { (n: 191) }\end{array}$ & $\begin{array}{l}\text { SIL-Ger score } \\
<70 \text { (n: 125) }\end{array}$ & $\mathbf{P}$ \\
\hline $\begin{array}{l}\text { Rate of participation in } \\
\text { the program }\end{array}$ & $149(78 \%)$ & $15(12 \%)$ & $<0.001$ \\
\hline Age (mean $\pm S D)$ & $25.4 \pm 0.7$ & $23.2 \pm 0.2$ & 0.06 \\
\hline Gravida & $1.5 \pm 2.1$ & $1.6 \pm 0.7$ & 0.42 \\
\hline Parity (mean $\pm S D$ ) & $1.5 \pm 0.4$ & $1.4 \pm 0.1$ & 0.18 \\
\hline $\begin{array}{l}\text { Gestational age at } \\
\text { delivery (week } \pm \text { SD) }\end{array}$ & $37.6 \pm 0.4$ & $38.0 \pm 0.6$ & 0.14 \\
\hline \multicolumn{4}{|l|}{ Education ( $\mathrm{n}, \%)$} \\
\hline - None & $25(13)$ & $42(27.6)$ & 0.02 \\
\hline - Primary & $14(7.3)$ & $17(13.6)$ & 0.62 \\
\hline - Secondary & $47(24.6)$ & $27(21.6)$ & 0.43 \\
\hline - High & $52(27.2)$ & $27(21.6)$ & 0.003 \\
\hline - University & $42(21.9)$ & $19(15.2)$ & $<0.001$ \\
\hline - Master's degree & $4(2)$ & $0(0)$ & $<0.001$ \\
\hline Birth weight $(\mathrm{g} \pm \mathrm{SD}$ ) & $3082 \pm 120$ & $3320 \pm 312$ & 0.48 \\
\hline $\begin{array}{l}5^{\text {th }} \text {-minute APGAR score } \\
(\text { mean } \pm S D)\end{array}$ & $9.3 \pm 1.5$ & $8 \pm 0.3$ & $<0.001$ \\
\hline VAS score $($ mean $\pm S D)$ & $7.21 \pm 0.33$ & $9.33 \pm 0.41$ & $<0.001$ \\
\hline
\end{tabular}

SIL — Salmon's Item List; SD — standard deviation; VAS — Visual Analog Scale

women who had high school degrees, who were university graduates, and who had master's degree in the group with SIL scores more than 70 (27.2\%, $21.9 \%, 2 \%)$ was significantly higher than those below SIL score $70(p=0.003, p<0.001$, $\mathrm{p}<0.001$, respectively); and in the group with SIL score below 70, those with none school education at all were significantly more $(p=0.02)$. Again, VAS scores were detected to be lower in the group with SIL scores above 70 compared to those with SIL score below $70(p<0.001)$. The rate of those with SIL scores over 70 in participating in the birth preparation program was significantly higher than those with SIL score lower than $70(78 \%, 12 \%$, respectively; $p<0.001)$.

\section{DISCUSSION}

It was found in the present study that the birth satisfaction rates of pregnant women who participated in the birth preparation program, which lasted four months and which 
was a 12-hour program, were higher than those who did not participate in these programs. It was also found that the postpartum VAS scores of the pregnant women who participated in this training program were lower.

Several studies were conducted to examine the relation of satisfaction during pregnancy and during delivery with various demographic data like age, parity, birth type or educational level, and profession [14-16]. As a result of these studies, no full consensus was reached, and contradictions emerged. Although studies are reporting that birth satisfaction is related to the educational level, age, and income status [14], there are also some studies arguing that there are no associations between satisfaction and demographic data [16]. Among the patients who had SIL scores more than 70, the number of those who had a high school, university, and master's degrees was higher at significant levels compared to those with SIL scores below 70. It was also determined that $78 \%$ of the patients with SIL scores above 70 participated in the birth preparation program. In other words, according to our study, higher education levels might be effective in high satisfaction rates during delivery.

One of the most important parameters determining satisfaction during childbirth is a pain because it is known that birth is one of the most painful processes in human life [17]. It was reported in a previous study that pain perception was associated with low SIL scores [14]. In our study, it was found that postpartum VAS scores were lower and SIL scores were significantly higher in women who participated in the birth preparation program. However, contrary to this, a systematic review speculated that the satisfaction of birth experiences was not related to the elimination of pain, but was related with how much the expectations of the pregnant woman were met, how the attitudes and behaviors of the healthcare employees who served her were, and how good their communication was [18]. It is possible that the SIL results and satisfaction levels were high in our study since the pregnant women, who participated in the birth preparation program, were told what they could face during this process and how to control the process. In other words, the active participation of the pregnant women in this process and the fact that the birth becomes controlled in this way might have caused that the pain was felt less and the satisfaction was higher. It was found in a systematic review conducted in 2008 that antenatal training was effective for pregnant women in terms of active participation in the delivery process, and had the potential to make conscious decisions [19].

The duration and contents of antenatal training vary among countries or according to healthcare organizations that provide obstetrics services. Different training programs are varying between up to one year or one-day training. Although there are arguments regarding the ef- fects of these different periods on antenatal training, it was reported that long-term birth preparation programs might be useful during the labor process because they include additional training like exercises, yoga, Pilates, pelvic floor training, breathing techniques, and stretching movements, etc. [5, 7]. A long-term birth preparation program was implemented in our study. Practical breathing exercises, pelvic floor exercises, and yoga training were also offered in this training. The total SIL scores of the pregnant women, who participated in this training, were found to be significantly higher compared to those who did not participate in this program $(108.5 \pm 4.2,79 \pm 3.5$, respectively). Similarly, the VAS scores were also found to be lower $(7.0 \pm 0.6,9.1 \pm 0.5$, respectively). Also, when fetal results were evaluated, it was found that the APGAR scores of the infants of the pregnant women with SIL scores more than 70 were higher than those with SIL scores lower than $70(9.3 \pm 1.5,8 \pm 0.3$, respectively). In this context, it is possible to argue that our birth preparation program was effective because $78 \%$ of the patients with SIL scores above 70 participated in antenatal training.

It was reported that antenatal training improved the rate of breastfeeding and provided women with the necessary information about breastfeeding $[20,21]$. However, no evaluations were made in our study regarding breastfeeding. Although publications are arguing that antenatal training increases vaginal birth rates $[22,23]$, several others do not support these data $[2,24]$. In a study including 1193 cases that received and that did not receive antenatal training, it was reported that pregnant women who received training admitted to the hospital while they were actively in delivery action and that they needed epidural anesthesia less. Besides, cesarean section rates were found to be similar among groups [25]. In another study that compared 197 nulliparous women who received antenatal training and who did not receive, it was found that there were no significant differences between birth type and pain scores [9]. In our study, the effect of antenatal training on the birth type was not investigated. However, the cesarean section rate was $9.7 \%$ in the group that received training and $9.2 \%$ in the group that did not receive any training. The reason why no comparisons were made regarding the birth type in our study was that not only nulliparous patients but also patients who gave vaginal birth previously and who had a cesarean section. In other words, participation in the antenatal training was designed independently from the way of birth. For this reason, the effect of antenatal training on the birth type was not investigated.

There were some limitations to the present study. First of all, the study was conducted in single-centered fashion, and since it was a survey study, patients' educational status, literacy, perception levels of the questions or socio-demographic data might have affected the answers to the ques- 
tions. Another limitation was that it was not the case in the study like including only nulliparous, only multiparous, or only cesarean patients in it. All patients who applied and completed antenatal training were included in the study regardless of their birth types. For this reason, the effect of antenatal training on the birth type could not be investigated. Also, although there is breastfeeding training in the birth preparation program, no evaluations regarding breastfeeding were made in the present study. However, the strength of our study was that unlike the studies conducted on birth satisfaction, the SIL scale was used in this study, which increased the reliability of the answers because the content of the questionnaire is easy. Also, the number of patients in the study was not less compared to other studies.

\section{CONCLUSIONS}

In conclusion, birth preparation programs help pregnant women to engage in the process actively and become part of the team. Such programs also increase the satisfaction during delivery and the comfort of the postpartum period and reduce the traumas that might occur in the following births. For this reason, such programs must be disseminated to ensure that women can feel comfortable during both the birth process and the postpartum process.

\section{Acknowledgements}

We have no acknowledgements to be mentioned. All authors declare that they received no funding for this study.

\section{Conflict of interest}

The authors report no conflict of interest.

\section{REFERENCES}

1. Moos MK. Prenatal care: limitations and opportunities. J Obstet Gynecol Neonatal Nurs. 2006; 35(2): 278-285, doi: 10.1111/j.1552-6909.2006.00 039.x, indexed in Pubmed: 16620256.

2. Gagnon AJ, Sandall J. Individual or group antenatal education for childbirth or parenthood, or both. Cochrane Database Syst Rev. 2007(3): CD002869, doi: 10.1002/14651858.CD002869.pub2, indexed in Pubmed: 17636711.

3. Sioma-Markowska U, Poręba R, Machura M, et al. Paternal engagement during childbirth depending on the manner of their preparation. Ginekol Pol. 2016; 87(9): 639-643, doi: 10.5603/GP.2016.0059, indexed in Pubmed: 27723071.

4. Maliszewska K, Świątkowska-Freund M, Bidzan M, et al. Relationship, social support, and personality as psychosocial determinants of the risk for postpartum blues. Ginekol Pol. 2016; 87(6): 442-447, doi: 10.5603/GP.2016.0023, indexed in Pubmed: 27418222.

5. Ip WY, Tang CSk, Goggins WB. An educational intervention to improve women's ability to cope with childbirth. J Clin Nurs. 2009; 18(15): 2125-2135, doi: 10.1111/j.1365-2702.2008.02720.x, indexed in Pubmed: 19583645.

6. Kızılırmak $A$, Başer $M$. The effect of education given to primigravida women on fear of childbirth. Appl Nurs Res. 2016; 29: 19-24, doi: 10.1016/j.apnr.2015.04.002, indexed in Pubmed: 26856483.
7. Miquelutti MA, Cecatti JG, Makuch MY. Antenatal education and the birthing experience of Brazilian women: a qualitative study. BMC Pregnancy Childbirth. 2013; 13: 171, doi: 10.1186/1471-2393-13-171, indexed in Pubmed: 24007540 .

8. Slade $\mathrm{P}, \mathrm{MacPherson} \mathrm{SA}$, Hume A, et al. Expectations, experiences and satisfaction with labour. Br J Clin Psychol. 1993; 32(4): 469-483, doi: 10.1111/j.2044-8260.1993.tb01083.x, indexed in Pubmed: 8298545.

9. Fabian HM, Rådestad IJ, Waldenström U. Childbirth and parenthood education classes in Sweden. Women's opinion and possible outcomes. Acta Obstet Gynecol Scand. 2005; 84(5): 436-443, doi: 10.1111/j.0001-6349. 2005.00732.x, indexed in Pubmed: 15842207.

10. Sawyer A, Ayers S, Abbott J, et al. Measures of satisfaction with care during labour and birth: a comparative review. BMC Pregnancy Childbirth. 2013; 13: 108, doi: 10.1186/1471-2393-13-108, indexed in Pubmed: 23656701.

11. Bertucci V, Boffo M, Mannarini S, et al. Assessing the perception of the childbirth experience in Italian women: a contribution to the adaptation of the Childbirth Perception Questionnaire. Midwifery. 2012; 28(2): 265274, doi: 10.1016/j.midw.2011.02.009, indexed in Pubmed: 21489665.

12. Salmon $\mathrm{P}$, Miller R, Drew NC. Women's anticipation and experience of childbirth: the independence of fulfillment, unpleasantness and pain. $\mathrm{Br}$ J Med Psychol. 1990; 63 ( Pt 3): 255-259, doi: 10.1111/j.2044-8341.1990. tb01617.x, indexed in Pubmed: 2245201.

13. Stadlmayr W, Bitzer J, Hösli I, et al. Birth as a multidimensional experience: comparison of the English- and German-language versions of Salmon's Item List. J Psychosom Obstet Gynaecol. 2001; 22(4): 205-214, doi: 10.3109/01674820109049975, indexed in Pubmed: 11840574.

14. Spaich $S$, Welzel $G$, Berlit $S$, et al. Mode of delivery and its influence on women's satisfaction with childbirth. Eur J Obstet Gynecol Reprod Biol. 2013; 170(2): 401-406, doi: 10.1016/j.ejogrb.2013.07.040, indexed in Pubmed: 23962715.

15. Dannenbring D, Stevens MJ, House AE. Predictors of childbirth pain and maternal satisfaction. J Behav Med. 1997; 20(2): 127-142, doi: 10.1023/a:1025526610524, indexed in Pubmed: 9144036.

16. Waldenström U. Experience of labor and birth in 1111 women. J Psychosom Res. 1999; 47(5): 471-482, doi: 10.1016/s0022-3999(99)00043-4, indexed in Pubmed: 10624845.

17. Koutsospyros D, Epstein L. Pain in Pregnancy and Labor. Academic Pain Medicine. 2019: 305-309, doi: 10.1007/978-3-030-18005-8_39.

18. Hodnett ED. Pain and women's satisfaction with the experience of childbirth: a systematic review. Am J Obstet Gynecol. 2002; 186(5 Suppl Nature): S160-S172, doi: 10.1067/mob.2002.121141, indexed in Pubmed: 12011880

19. Lally JE, Murtagh MJ, Macphail S, et al. More in hope than expectation: a systematic review of women's expectations and experience of pain relief in labour. BMC Med. 2008; 6: 7, doi: 10.1186/1741-7015-6-7, indexed in Pubmed: 18366632.

20. Kronborg $\mathrm{H}$, Maimburg RD, Væth $\mathrm{M}$. Antenatal training to improve breast feeding: a randomised trial. Midwifery. 2012; 28(6): 784-790, doi: 10.1016/j.midw.2011.08.016, indexed in Pubmed: 22018394.

21. Yang X, Gao LL, Ip WY, et al. Predictors of breast feeding self-efficacy in the immediate postpartum period: A cross-sectional study. Midwifery. 2016; 41: 1-8, doi: 10.1016/j.midw.2016.07.011, indexed in Pubmed: 27479635.

22. METE S, ÇIÇEK Ö, TOKAT MA, et al. The Effect of Childbirth Preparation Classes on Fear of Childbirth, Birth Preference and Preparation of Labor. Turkiye Klinikleri Journal of Nursing. 2017; 9(3): 201-206, doi: 10.5336/nurses.2016-53977.

23. Serçekuş $P$, Başkale $H$. Effects of antenatal education on fear of childbirth, maternal self-efficacy and parental attachment. Midwifery. 2016; 34: 166-172, doi: 10.1016/j.midw.2015.11.016, indexed in Pubmed: 26656473.

24. Walker DS, Visger JM, Rossie D. Contemporary childbirth education models. J Midwifery Womens Health. 2009; 54(6):469-476, doi: 10.1016/j. jmwh.2009.02.013, indexed in Pubmed: 19879519.

25. Maimburg RD, Vaeth M, Dürr J, et al. Randomised trial of structured antenatal training sessions to improve the birth process. BJOG. 2010; 117(8): 921-928, doi: 10.1111/j.1471-0528.2010.02584.x, indexed in Pubmed: 20536430 